\title{
Maximizing Power Output of a Partially Shaded Total-Cross-Tied Photovoltaic array
}

\author{
Neha S. Shah and Hiren H. Patel
}

\begin{abstract}
Non-uniform conditions on the modules of the PV array, especially, partial shading reduces the output of the PV array to a large extent. The shaded module in a string limits the current of the entire string and hence, the output power of the string. The output power under such conditions is reported to be higher for total-cross-tied (TCT) configuration. This paper describes two different approaches, one based on current compensation (current equalization) and another based on voltage equalization, to extract higher power from the partially shaded total-cross-tied photovoltaic array. The TCT configuration is considered to minimize the number of converters, sensors, cost and complexity involved. The additional converters in the two distinct approaches evaluated here operate only when the partial shading occurs and are controlled to minimize the current and voltage miss-matches. The analysis and the control algorithm are presented. Simulation results obtained in MATLAB/Simulink are included to demonstrate the effectiveness of both methods and the relative merits and demerits of these approaches are highlighted.
\end{abstract}

Keywords - Current compensation, voltage equalization, MPPT, partial shading, TCT configuration.

\section{INTRODUCTION}

Now-a-days, energy generation from renewable energy sources has increased tremendously due to the increasing concern about the environment, technological advancements and decreased cost of renewable technology. Amongst all the renewable sources, Solar photovoltaic (PV) has emerged as the most popular and prominent source in the last decade, mainly due to bundle of advantages like low maintenance, no operating cost, pollution free, modular nature, etc. The cost of the PV modules has also decreased greatly over the years thereby reducing pay-back period.

However, to ensure that the pay-back period is kept to the minimum, it must be ensured that the PV array always operate at or near to its peak power. The peak power available from the PV array is dependent on various parameters like irradiation, temperature, configurations, aging of the modules, module parameters, dusting, miss-match in modules, shading pattern on the array etc. Normally, the output power versus voltage $(P-V)$ characteristics of the $\mathrm{PV}$ module or an array operating under uniform conditions is characterized by a curve having only one peak. Though the peak power available from

N. S. Shah is with the Department of Electrical Engineering, SardarVallabhbhai Patel Institute of Technology, Vasad, India. (e-mail: neha_saurabh_shah@yahoo.com).

H. H. Patel is with the Department of Electrical Engineering, Sarvajanik College of Engineering \& Technology, Surat, India. (e-mail: hiren.patel@scet.ac.in). the PV array varies as the irradiation and/or temperature changes, due to the uni-modal (single peak) nature of the $P-V$

characteristics, it is easy to track the maximum power point (MPP) with conventional maximum power point tracking (MPPT) techniques[1],[2]. In addition the fact that the MPP occurs corresponding to $75 \%$ to $80 \%$ of the open-circuit voltage $\left(V_{O C}\right)$ of the array or corresponding to $90 \%$ of the short-circuit current $\left(I_{S C}\right)$ can also be exploited to locate the MPP.

Unlike the array operating under uniform conditions, the array operating under non-uniform conditions exhibits much complex output current and voltage $(I-V)$ and $P-V$ characteristics. The $I-V$ characteristic under such case has more than one step, while the $P-V$ characteristic possesses more than one peak: one global peak (GP) and other local peaks. The conventional MPPT techniques are no longer effective to track the GP under such conditions. Hence, tracking of GP to extract the maximum power from PV array operating in partial shading condition is a challenging task. Various global peak power point tracking (GPPPT) approaches have been reported[2]-[4]. Although these approaches can track the GP, the power is still less than the summation of maximum power that all modules can generate if operating independently. The distributed maximum power point tracking (DMPPT) operates on this concept of maximizing the output of each module by applying dedicated MPP tracker with each module. Thus, in DMPPT the selfcontrol DC-DC power modules connected across each PV module helps to operate individual PV module on their maximum power thereby avoiding scenario which has multiple peaks[5]-[8]. Irrespective of the uniform or nonuniform irradiance conditions, the output power of PV array is always processed through the DC-DC converters used as MPP trackers. Hence, the same DC-DC converters, which helps in improving the output power and efficiency in partially shaded conditions, results in the decrease in efficiency of the PV system when operating under uniform irradiance. The cost and complexity of the system is also higher.

An alternative to overcome the losses occurring in the converter during uniform irradiance condition is current equalization based MPPT[9]-[11]. In this method, isolated DC-DC converter is connected across each PV module. Unlike DMPPT, the converters remain idle during uniform irradiance conditions and come into effect only when partial shading occurs. Also, the converters are designed to handle just the miss-match power. However, more sensors are required to measure individual MPPT and also system gets periodically disconnected from the load to measure individual 
module $I-V$ characteristics [11],[12]. The approach increases the reliability and output power considerably under severe non-uniform conditions, however at an increased complexity and cost. Another limitation of the approach is the losses in the sensing and signal conditioning circuit that occurs continuously, irrespective of status of current equalization control: active or idle.

Another approach where losses in the converters are eliminated by keeping them ineffective during uniform irradiance conditions is the Generation Control Circuit (GCC). A multi-stage chopper is employed with one chopper connected across each module in a string[13],[14]. To extract maximum power from PV module in partially shaded condition, the off-duty cycle of multi stage choppers are controlled in such a way that the charge equalization (voltage equalization) occurs across the modules connected in strings.

The current compensation is applied to the TCT configuration [15] with a view to reduce the number of converters. PV modules can be connected in different configuration e.g. Series, Parallel, Series Parallel (SP), Total Cross Tied (TCT) and Bridge Link (BL) [16]-[21]. Output power in TCT configuration is high as compared to SP configuration under partial shading condition [16]-[21]. Thus, the current compensation with TCT provides a better solution and leads to the reduction in number of converters, sensors and hence, the cost and complexity of the system. Also, PV modules always remain connected to the load/ grid [15].

This paper presents and evaluates two different approaches for enhancing the power output of a partially shaded array. With a view to minimize cost of PV system and yet to have maximum possible power from the PV array under uniform and non-uniform insolation conditions, the TCT configuration is considered. Two different approaches: one based on current compensation (CC) and another that employs concept of Generation Control Circuit (GCC) and is based on voltage equalization principle, are presented and evaluated.

\section{CURRENT COMPENSATION FOR TCT CONFIGURATION}

\section{A. System Configuration}

Current Compensation for TCT configuration of ' $n$ ' ties, where each tie comprises of ' $m$ ' modules is shown in Fig 1(a). The PV module $\mathrm{PV}_{\mathrm{ij}}$ indicates $j^{\text {th }}$ module of $i^{\text {th }}$ tie. Capacitor $C_{o u t}$ is connected across series connected PV ties which not only acts as a filter to minimize the ripple in the PV array's output voltage, but also serves as the input to ' $n$ ' DC-DC converters. The DC-DC converters connected across ties, tap the power from decoupling capacitor and utilize it to minimize the current discrepancies among the series connected ties [15]. As all the DC-DC converters are fed from the same capacitor, $C_{\text {out }}$, it is must to have isolation in the DC-DC converters. Hence, flyback converter topology shown in Fig. 1(b) is employed for DC-DC converters. Also, it handles only the power required to match the difference in the currents of series connected ties.

Irrespective of the irradiance level on the modules in the tie, as the voltage at which the maximum power point occurs

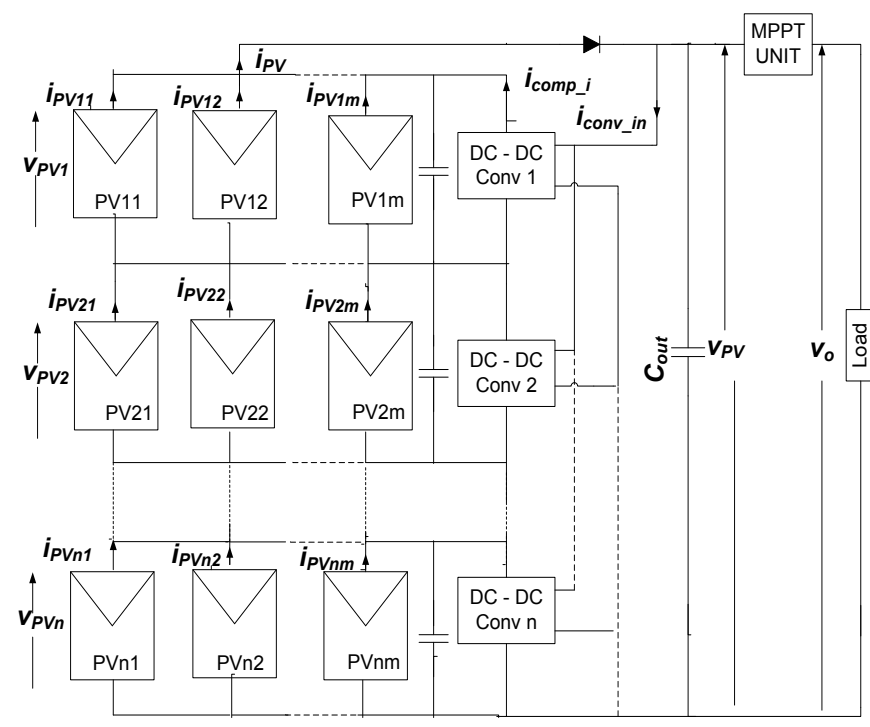

(a)

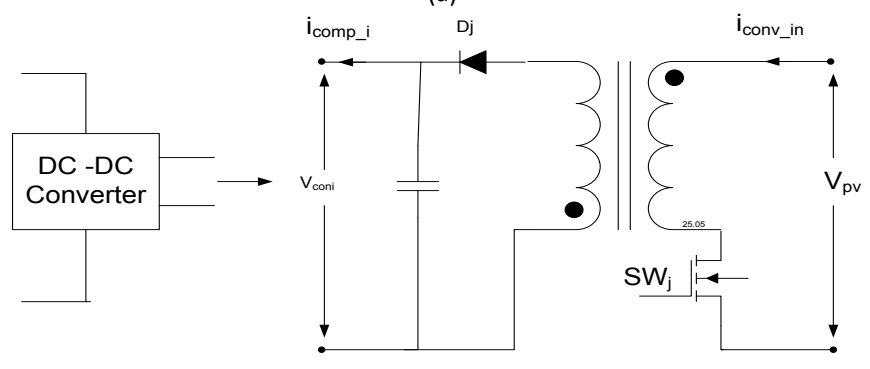

(b)

Fig 1(a) Current Compensation for TCT configuration (TCT-CC). (b) flyback converter [15]

remains nearly the same, the maximum power from all the modules of the tie can be extracted if the tie is made to operate at this specified voltage. If the modules in the tie have different irradiance, they all can be controlled to operate near their individuals MPP by maintaining the voltage across them near to that corresponding to the MPP under uniform insolation condition The current supplied by the different modules in the tie is different (corresponding to their irradiance level). The different ties may be generating different currents depending on the irradiance received by the ties. Flyback converters are controlled to output current such that the total current of the tie and its associated flyback converter is equal to the current generated by the least shaded tie (i.e. the tie generating the highest current).

The efficiency of flyback convert is considered as $90 \%$. So the input rating of the converter is $P / 0.9$. where $\mathrm{P}$ is the output power of converter

$$
P=v_{\text {convi }} \times i_{\text {comp_ }^{i}}
$$

where $i_{\text {comp } \_}$is the compensating current from $i^{\text {th }}$ converter and $v_{c o n v i}$ is output voltage of $i^{\text {th }}$ converter. The flyback converter's output voltage is controlled by controlling duty cycle of switch $S W_{i}$ using $v_{c o n v i}$ as reference voltage, which is obtained through the algorithm presented in [15]. The output voltage $v_{\text {convi }}$ and current $i_{\text {comp }} i$ of the Flyback converters for $i^{\text {th }}$ tie are given by: 


$$
\begin{aligned}
v_{\text {convi }} & =\frac{N_{2}}{N_{1}} \times\left(\frac{D_{i}}{1-D_{i}}\right) \times V_{P V} \\
i_{\text {comp } i} i & =\frac{N_{1}}{N_{2}} \times\left(\frac{1-D_{i}}{D_{i}}\right) \times i_{\text {conv_in }}
\end{aligned}
$$

where $N_{I}$ and $N_{2}$ are the turns of primary and secondary winding of flyback transformer, $V_{P V}$ is the voltage across decoupling capacitor, $D_{i}$ is duty cycle of $i^{\text {th }}$ converter and $i_{\text {conv_in }}$ is the input current of $i^{\text {th }}$ flyback converter. Total output voltage and current of PV array with the TCT configuration are

$$
\begin{gathered}
V_{P V}=\sum_{i=1}^{n} V_{P V i} \\
i_{P V}=i_{\text {comp }_{-} i}+\sum_{j=1}^{m} i_{P V i j}
\end{gathered}
$$

where $V_{P V i}$ is the voltage across $i^{t h}$ tie and $i_{P V i j}$ is the current generated by the module $\mathrm{PV}_{\mathrm{ij}}$.

Total power supplied to flyback converters is

$$
P_{\text {flyback }}=\sum_{i=1}^{n} v_{\text {convi }} \times i_{\text {comp_ } i}
$$

and hence the net power supplied is

$$
P_{\text {net }}=V_{P V} \times i_{P V}-P_{\text {flyback }}
$$

\section{B. Control Algorithm}

Initially all the flyback converters are inactive and the main boost converter operates to track the MPP, which may not be the optimum operating point. The voltage across each tie is measured and compared to detect whether shading has occurred or not. If all the ties have same voltage, then it indicates that the modules have uniform irradiance. If any mismatch in the voltage across ties is detected, it indicates that shading has occurred. The tie experiencing shading is characterized by lesser voltage than that having less or no shading. Flyback converter of the shaded tie is controlled to minimize current mismatch. The duty cycle of main boost converter is kept constant during this phase. The duty cycle of converter of shaded tie is adjusted such that the voltage across shaded tie increases with a condition that the total voltage across all the ties remains constant. This results into increase in the output power from the shaded modules. The detailed control algorithm of the TCT-CC method is shown in Fig 2.

In TCT configuration, only one flyback converter is assigned with each tie, resulting in a reduction in the number of flyback converters required compared to that for SP configuration. The main advantage of TCT configuration is the reduction in the number of sensors, signal conditioning circuits and the associated losses which occurs even in case when they are not active (i.e. under uniform irradiation on all ties). The main drawback of this method is the low power handling capability of about $150-200 \mathrm{~W}$ by the flyback converter. Flyback converter is operated at high frequency generally $1 \mathrm{kHz}-50 \mathrm{kHz}$ and power rating of the converter is

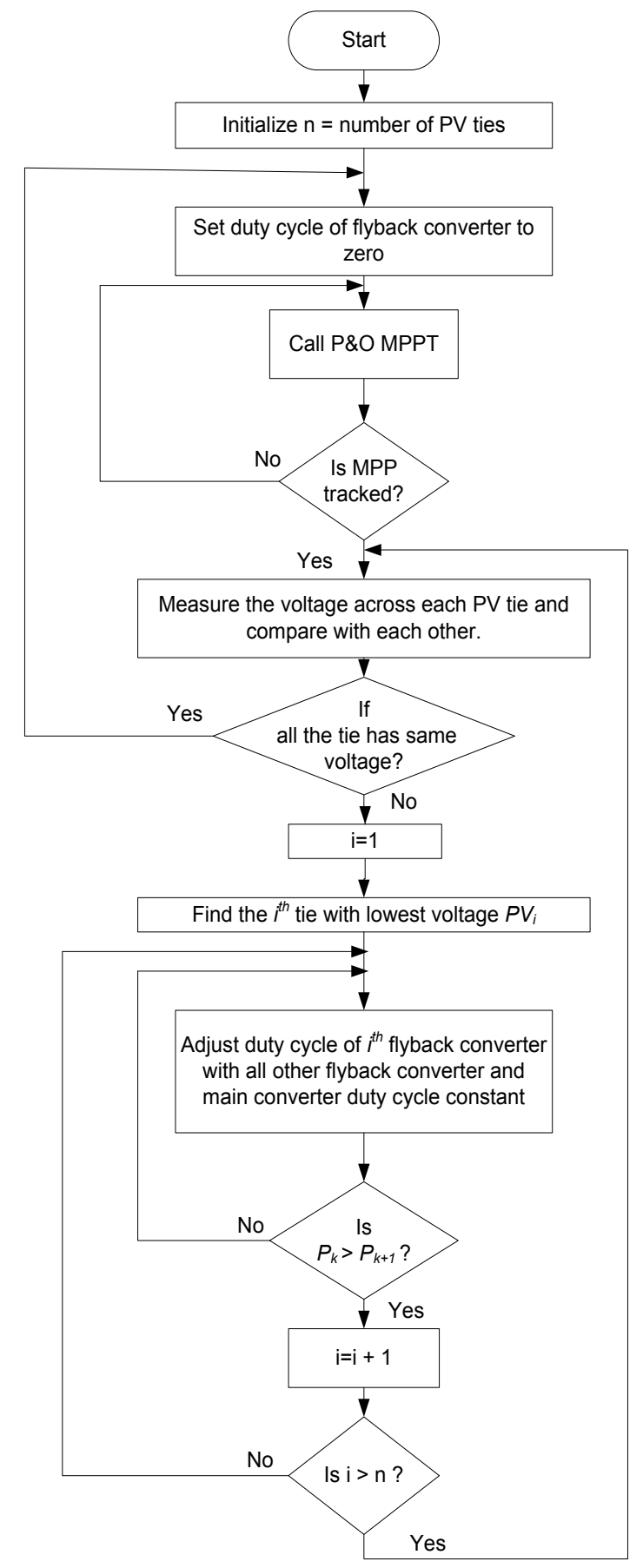

Fig. 2 Algorithm of TCT-CC method for MPPT

decided by the voltage at MPP of any of the ties under uniform insolation conditions and the compensating current required to be injected from the converter under the worst possible condition.

\section{GCC FOR TCT CONFIGURATION}

GCC concept [13], where GCC is used with each module of series connected string is extended for TCT configuration with 
a view to reduce the number of choppers required. Modified control algorithm is presented to extract the maximum power from the TCT-GCC configuration shown in Fig. 3.

\section{A. System Configuration of TCT-GCC}

Fig 3 shows a TCT-GCC configuration having ' $n$ ' ties. Each PV tie consists of ' $m$ ' PV modules. Here only ' $n$ ' number of multi-stage chopper circuit is required compared to ' $m \times n$ ' for SP configuration. The number of inductors required is $n-1$. The 'MPPT UNIT' shown in Fig.3 is a boost converter, which tracks the peak power point. Under uniform irradiance conditions when all the ties have same irradiance and generate similar output current, the gate-pulses to switches of TCT-GCC circuits are inhibited, making the TCT-GCC idle. Switch $S W_{i}$ along-with the anti-parallel diode provides the bidirectional current capability, thereby allowing the capability of exchanging the charge between the capacitors $C_{i}$. Thus, it provides the feature to achieve voltage equalization amongst the output voltages of all the ties. Anti-parallel diodes connected across each switch $S W_{i}$ can also work as conventional bypass diodes preventing the large negative voltage across the modules. Also, if the switches $S W_{i}$ fail, the main converter can still extract higher power from the partially shaded array by tracking the GP. Of course the power extracted from the array is less than the case when TCT-GCC is in operation, but certainly more than the case when bypass diodes are absent. To extract maximum possible power from the partially shaded PV array, the off-duty ratios of multistage choppers are controlled such that the output voltage of each $\mathrm{PV}$ tie is regulated near to the voltage corresponding to the maximum power point.

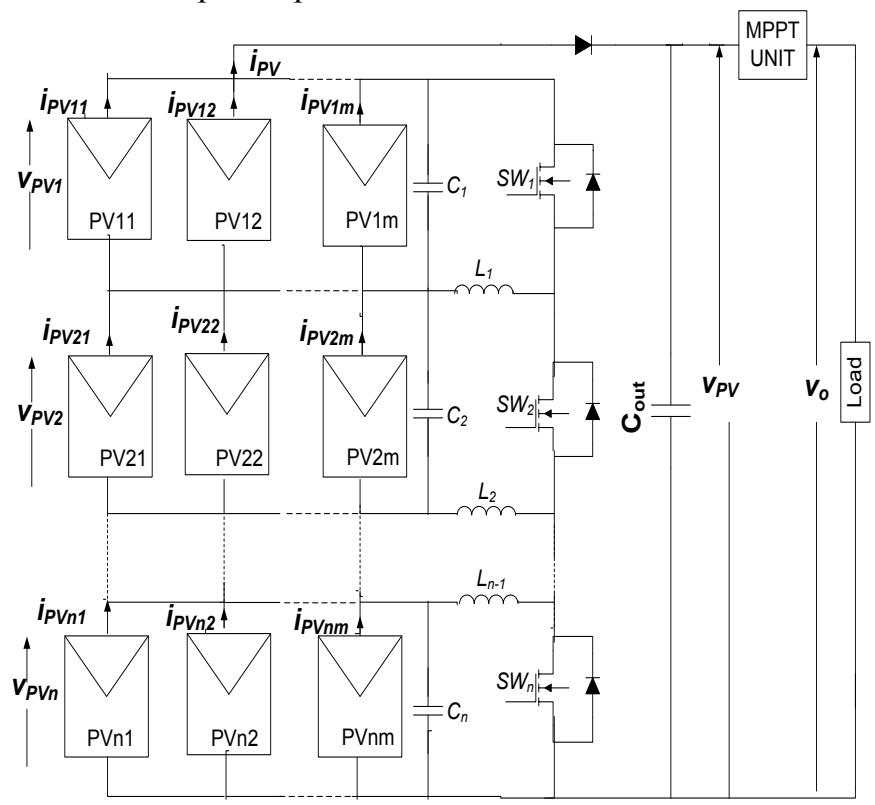

Fig 3 System configuration for TCT-GCC method

The relationship between the voltage across each PV module and the off-duty ratios of each switches of the TCTGCC are expressed in (8).

$\overline{D_{1}}: \overline{D_{2}}: \ldots .: \overline{D_{i}}: \ldots .: \overline{D_{n}}=V_{P V 1}: V_{P V 2}: \ldots . V_{P V i}: \ldots . V_{P V n}$ where $\overline{D_{i}}$ is off-duty ratio of switch $S W_{i}$.

$$
\overline{D_{i}}=\frac{T_{i(O F F)}}{T_{s w}}
$$

where $T_{i(O F F)}$ is the OFF time of switch $S W_{i}$ and $T_{S w}$ is the switching time interval.

$$
\sum_{i=1}^{n} \overline{D_{i}}=1
$$

The off-duty ratio of $i^{\text {th }}$ tie depends on generation control voltage of $i^{\text {th }}$ tie $V_{P V i}$ and input voltage to boost converter $V_{P V}$.

$$
\overline{D_{i}}=\frac{V_{P V i}}{V_{P V}}
$$

The output current $i_{P V}$ of the system is given as

$$
\begin{gathered}
i_{P V}=\sum_{i=1}^{n} \overline{D_{i}} I_{i} \\
I_{i}=\sum_{j=1}^{m} i_{P V i j}
\end{gathered}
$$

where $I_{i}$ is the $i^{t h} \mathrm{PV}$ tie current and $i_{P V i j}$ is the current generated by the module $P V_{i j}$.

The output power $P_{\text {out }}$ of the system is

$$
P_{\text {out }}=V_{P V} \times i_{P V}=\sum_{i=1}^{n} V_{i} \times I_{i}
$$

\section{B. Control Algorithm of TCT-GCC configuration}

The algorithm of the TCT-GCC method is shown in fig. 4. Initially, all the multi-stage choppers are deactivated and the main Boost converter operates and tracks the peak which may not be the optimum operating point. The voltage across each tie of the TCT configuration is measured and compared to determine if partial shading has occurred or not. Once the partially shaded condition is detected, the duty-cycle of the main(boost) converter is kept constant and the duty ratios of choppers of TCT-GCC are adjusted. The off-duty ratio of the tie with lowest output voltage (maximum shading) is calculated and adjusted. The off-duty ratios of all choppers are adjusted so as to meet the conditions mentioned by (8)-(10). Continuously the tie with lowest voltage is identified and the off-duty ratios are adjusted to achieve voltage equalization amongst the ties. Periodically, the main converter is also activated to ensure that the operation is maintained at or near to MPP to extract the maximum possible output power. To achieve this, a flag is set periodically for a very small duration during which the main converter employs the conventional MPPT technique like Perturb and Observe(P\&O) or Incremental Conductance method. Thus, when flag is set duty cycles of multi-stage converters are kept constant and that of boost converter is adjusted as per $\mathrm{P} \& \mathrm{O}$ to set operating point of PV array for maximum output power. 


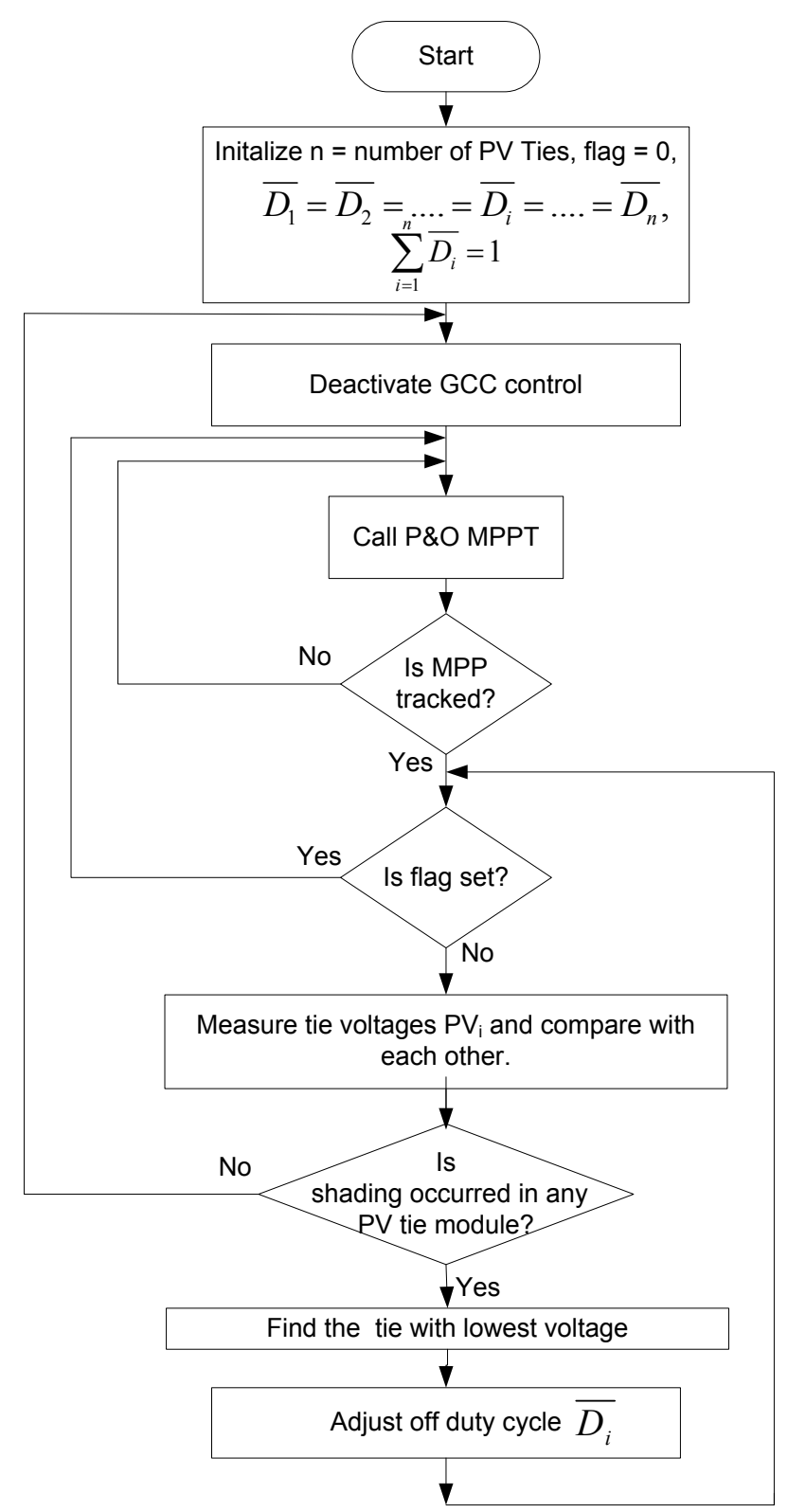

Fig 4. Algorithm of TCT-GCC technique for MPPT.

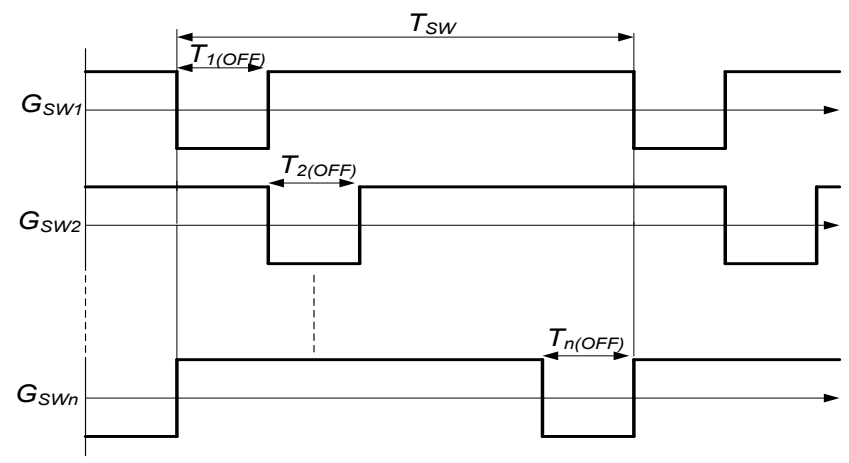

Fig 5 Gate signals of the multistage chopper for TCT-GCC.

Fig.5 shows the gate pulse sequence of switches $S W_{l}-S W_{n}$ in partially shaded condition. At any instant only one switch is turned off and total off-duty ratio of all switches is one.

\section{Simulation Results}

The algorithms of both the methods are simulated using MATLAB/Simulink software. This section presents results of the simulations and discusses the major observations. SOLAREX-MSX60 PV modules are considered for simulations. The specifications of the SOLAREX-MSX60 PV module at standard test conditions are shown in Table I.

TABLE-I

PV MOdULE SPECIFICATION AT $1000 \mathrm{~W} / \mathrm{M}^{2} .25^{\circ} \mathrm{C}$

\begin{tabular}{|c|c|}
\hline PV module Power & $60 \mathrm{~W}$ \\
\hline Open Circuit Voltage & $21 \mathrm{~V}$ \\
\hline Short Circuit Current & $3.8 \mathrm{~A}$ \\
\hline Voltage at MPP & $17.1 \mathrm{~V}$ \\
\hline Current at MPP & $3.5 \mathrm{~V}$ \\
\hline
\end{tabular}

Fig. 6 shows the system configurations considered for the evaluation of two approaches. Fig 6(a) shows system configuration for current compensation technique while Fig. 6(b) represents system configuration for TCT-GCC. In both cases, PV array comprises of two ties- each having two PV modules.

Initially at $\mathrm{t}=0 \mathrm{~s}$, all PV modules (PV11, PV12, PV21 and PV22) operate under same irradiance of $1000 \mathrm{~W} / \mathrm{m}^{2}$. At $\mathrm{t}=0.5 \mathrm{~s}$ partial shading occurs and the irradiance on the module PV21 and PV22 of tie- 2 decreases to $500 \mathrm{~W} / \mathrm{m}^{2}$. At $\mathrm{t}=3 \mathrm{~s}$ irradiance on PV12 module decreases to $800 \mathrm{~W} / \mathrm{m}^{2}$ with other PV module still having earlier irradiance (that prevailing before $\mathrm{t}=3 \mathrm{~s})$.

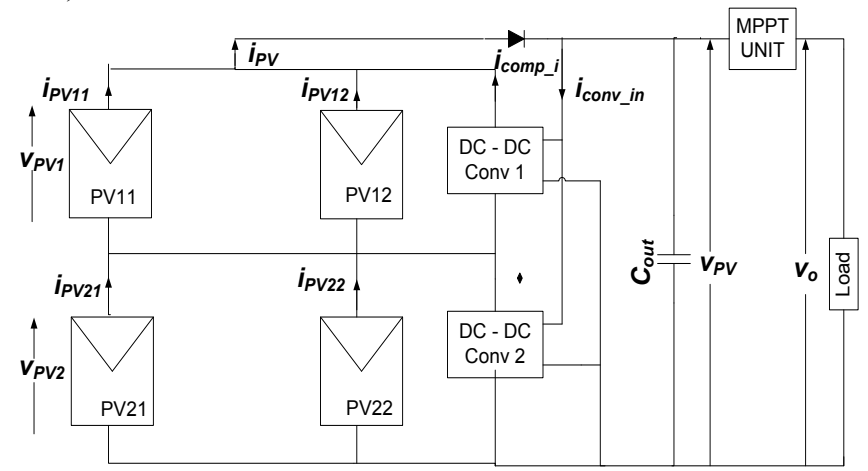

(a)

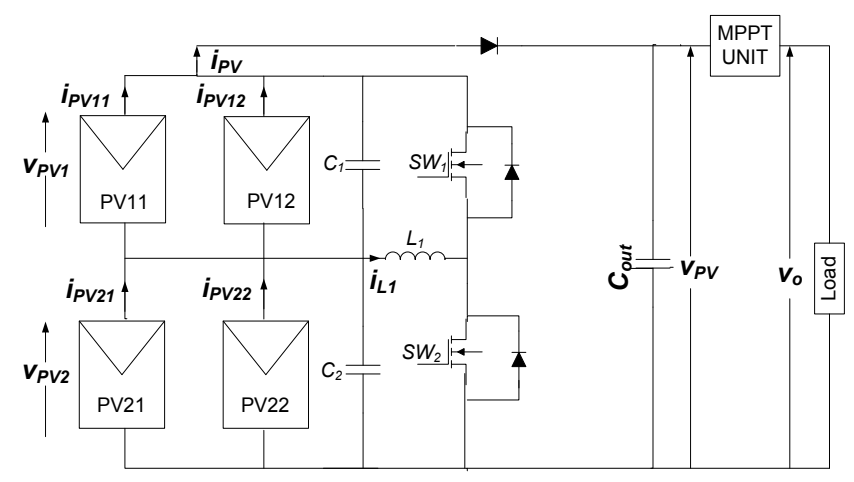

(b)

Fig.6 System configurations having two ties for evaluating the two approaches: (a) TCT-CC[15] ; (b)TCT- GCC. 
Till $\mathrm{t}=0.5 \mathrm{~s}$, all $\mathrm{PV}$ modules have uniform irradiance of $1000 \mathrm{~W} / \mathrm{m}^{2}$. Hence, till $\mathrm{t}=0.5 \mathrm{~s}$ flyback converters in TCT-CC method and multistage choppers in TCT-GCC method do not operate. The main DC-DC converter tracks the peak through the $\mathrm{P} \& \mathrm{O}$ algorithm resulting into output power of about $240 \mathrm{~W}$ in both the cases. At $\mathrm{t}=0.5 \mathrm{~s}$ the partial shading occurs on the
PV array with lower irradiance on the module of tie-2. During $\mathrm{t}=0.5 \mathrm{~s}-0.9 \mathrm{~s}$, no converters are operated except main boost converter which is tracking the MPP. Output current and power is reduced to $3.8 \mathrm{~A}$ and $130 \mathrm{~W}$, respectively compared to $7 \mathrm{~A}$ and $240 \mathrm{~W}$ (available before $\mathrm{t}=0.5 \mathrm{~s}$ ) as shown in Fig.7.

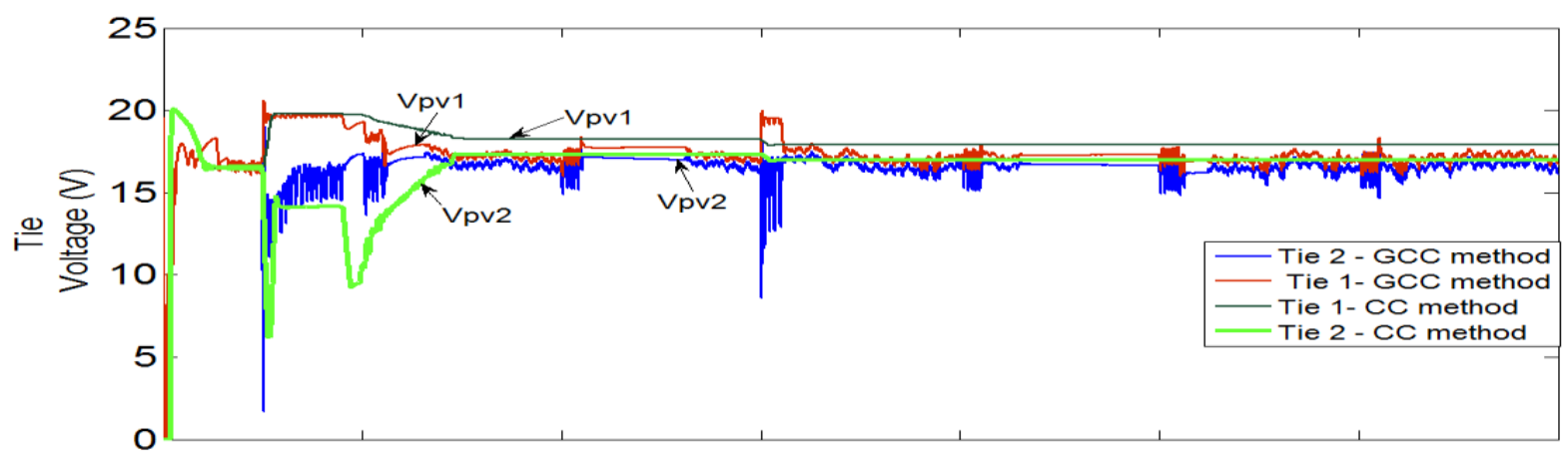

(a)

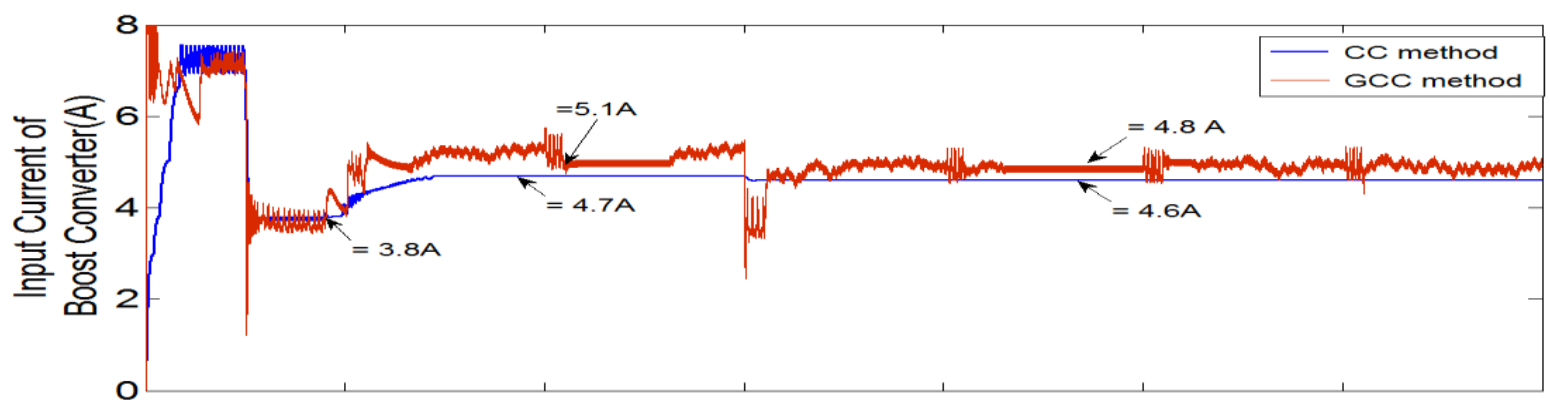

(b)

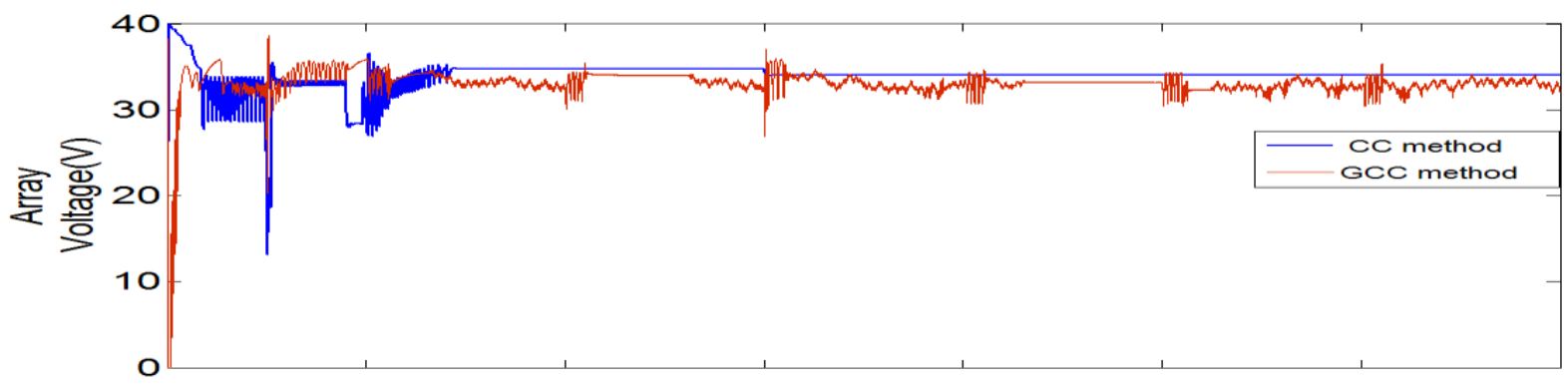

(c)

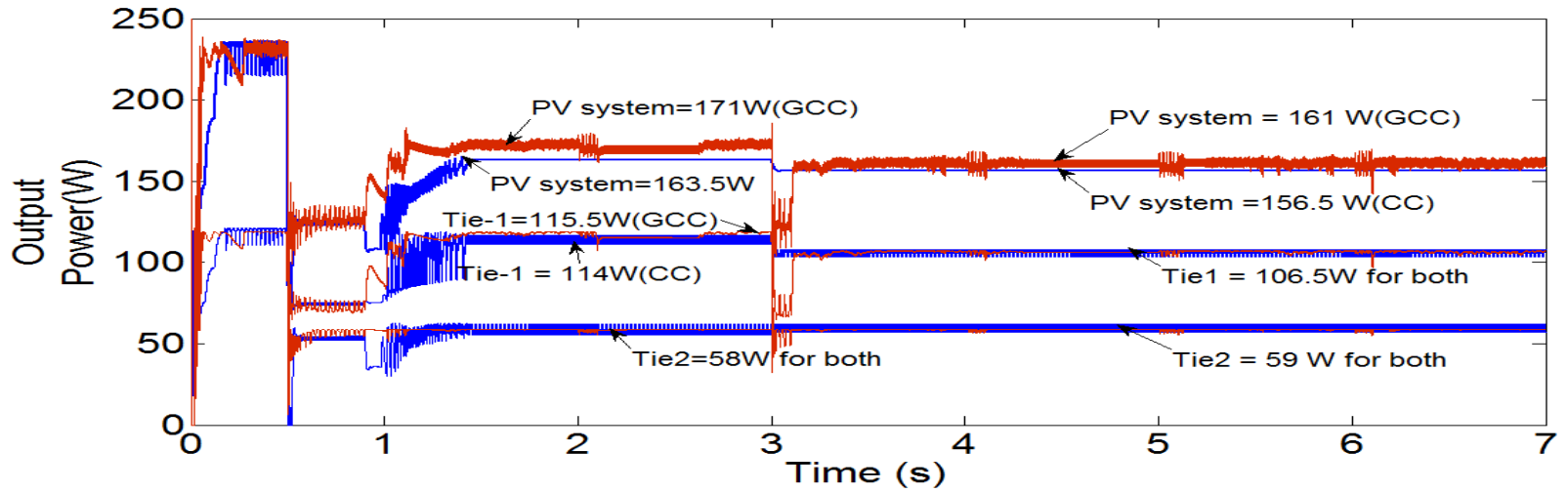

(d)

Fig. 7 Waveforms of (a) voltages of tie-1 and tie-2, (b) input current of boost converter, (c) PV array voltage and (d) power of tie-1, tie-2 and power fed to boost Converter 
At $\mathrm{t}=0.9 \mathrm{~s}$ flyback converters of TCT-CC method and multistage choppers of TCT-GCC method are activated. In TCT-CC method, voltage across tie-2 is increased in small steps and it injects current in tie- 2 to minimize the mismatch in current of both ties. This results in to increase in output current and power of PV system to $4.7 \mathrm{~A}$ and $163 \mathrm{~W}$, respectively. Fig. 7(d) shows that the total power extracted from the PV array is (Power of Tie1 + Power of Tie-2) = $114+58=172 \mathrm{~W}$ against the maximum $180 \mathrm{~W}$ that the modules of PV array could generate under the given scenario. Thus, the TCT-CC method is unable to track power of about $8 \mathrm{~W}$. Fig.7(d) also shows the power fed to the main DC-DC (boost) converter (referred as PV system power in Fig. 7(d)) is $163 \mathrm{~W}$, which is further $9 \mathrm{~W}$ less than that extracted from the PV array. The reduction is due to the losses in the flyback converters. The flyback converters are relatively less efficient as they involve indirect energy transfer. Thus, the difference of $17 \mathrm{~W}$ is due to the losses in the flyback converters and inaccuracy in tracking the MPP. When the irradiance on the PV12 module decreases to $800 \mathrm{~W} / \mathrm{m}^{2}$ at $\mathrm{t}=3 \mathrm{~s}$, the net output power of the $\mathrm{PV}$ system further reduces to $156.5 \mathrm{~W}$ against the $168 \mathrm{~W}$ available.

In TCT-GCC method at $\mathrm{t}=0.9 \mathrm{~s}$ multistage chopper is operated and duty cycle of main boost converter is held constant. The duty-cycles of the multi-phase choppers are adjusted to equalize the voltages across the two ties. Fig. 7(a) shows that the difference in the tie voltages with TCT-GCC is lesser than that with $\mathrm{CC}$ approach. Initially on the activation of TCT-GCC algorithm, the output power of the PV system is increased up to $150 \mathrm{~W}$, which is further increased to $171 \mathrm{~W}$ when the flag activates the boost converter for $\mathrm{P} \& \mathrm{O}$ control. In a pre-set program, the flag for activating the $\mathrm{P} \& \mathrm{O}$ control is periodically set after every one second and stays on for $0.01 \mathrm{~s}$ duration. During the period when the flag is set, the duty cycle of the boost converter is adjusted as per P\&O control while the duty cycles of multistage choppers are held constant. The output power extracted from the PV array and current is thus increased to $173.5 \mathrm{~W}$ (Powers of Tie- 1 and Tie- $2=115.5 \mathrm{~W}+$ $58 \mathrm{~W}=173.5 \mathrm{~W}$ ) and $5.1 \mathrm{~A}$, respectively. The total power fed to the boost converter is $171 \mathrm{~W}$, which is still $9 \mathrm{~W}$ less than $180 \mathrm{~W}$, the sum of maximum power that all modules can generate under the given conditions. The difference of $9 \mathrm{~W}$ is due to the power lost in multi-phase chopper $(2.5 \mathrm{~W})$ and power lost due to inaccuracy in tracking the MPP $(6.5 \mathrm{~W})$. After $\mathrm{t}=3 \mathrm{~s}$, the shading of PV12 module results into the decrease in the net power available from the PV system.

Under this condition, the power fed to boost converter with TCT-GCC approach is $161 \mathrm{~W}$ against the $156.5 \mathrm{~W}$ observed for TCT-CC approach. Thus, compared to TCT-CC technique, the TCT-GCC approach shows improvement of about $4.5 \%$ in the output power during the period $\mathrm{t}=0.9 \mathrm{~s}-3 \mathrm{~s}$ and $2.9 \%$ after $\mathrm{t}=3 \mathrm{~s}$ over.

Figs. 8(a), (b) and (c) show the zoomed view of tie voltages, input currents of boost converters and the PV array voltages for both the control approaches for the time range $\mathrm{t}=1.1 \mathrm{~s}-1.5 \mathrm{~s}$. It clearly shows that the tie voltages for TCTGCC are close to each other and around the voltage corresponding to MPP.

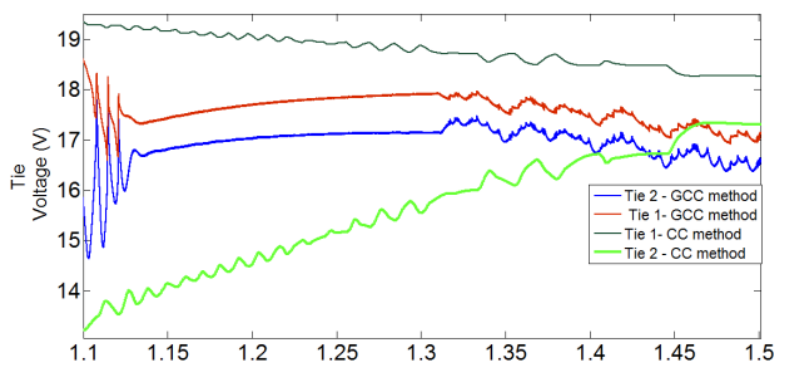

(a)

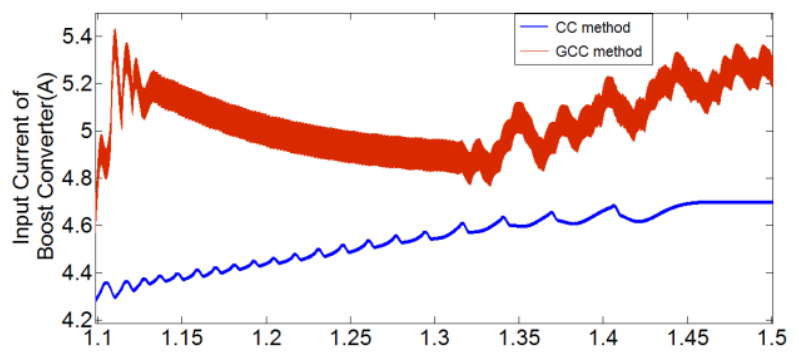

(b)

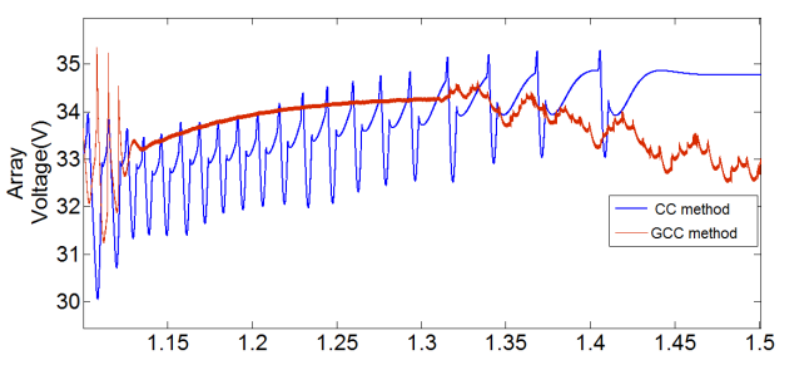

(c)

Fig. 8 Zoomed waveforms: (a) voltages of tie-1 and tie-2, (b) input current of boost converter, (c) PV array voltage

Each row of Table-II shows maximum output power of PV array with different shading pattern. $G_{-} P V_{i j}$ indicates the irradiance on $\mathrm{PV}$ module $\mathrm{PV}_{\mathrm{ij}}$, while $\bar{P}_{\text {o }_{-} \text {w } f c}$ stands for maximum power obtained in absence of flyback converters. $P_{o_{-} C C}$ represents the maximum power tracked with TCT-CC method and $P_{O_{-} G C C}$ represents the maximum power tracked with TCT-GCC method. It is observed that the GCC method significantly enhances the amount of output power of the array under partially shaded conditions compared to TCT-CC method.

TABLE-II

MPP POWER OF PV ARRAY UNDER VARIOUS IRRADIANCE CONDITIONS FOR CC AND GCC METHOD.

\begin{tabular}{|c|c|c|c|c|c|c|c|}
\hline $\begin{array}{c}G_{-} P V_{I I} \\
\left(\mathrm{~W} / \mathrm{m}^{2}\right)\end{array}$ & $\begin{array}{c}G_{-} P V_{12} \\
\left(\mathrm{~W} / \mathrm{m}^{2}\right)\end{array}$ & $\begin{array}{c}G_{-} P V_{21} \\
\left(\mathrm{~W} / \mathrm{m}^{2}\right)\end{array}$ & $\begin{array}{c}G_{-} P V_{22} \\
\left(\mathrm{~W} / \mathrm{m}^{2}\right)\end{array}$ & $\begin{array}{c}P_{o_{-} \text {wo } f c} \\
(\mathrm{~W})\end{array}$ & $\begin{array}{c}P_{o_{-} C C} \\
(\mathrm{~W})\end{array}$ & $\begin{array}{c}P_{o_{-} G C C} \\
(\mathrm{~W})\end{array}$ & $\begin{array}{c}\sum P_{i j \max } \\
(\mathrm{W})\end{array}$ \\
\hline 1000 & 1000 & 1000 & 1000 & 235 & ---- & ---- & 240 \\
\hline 1000 & 1000 & 1000 & 500 & 171 & 200 & 203 & 210 \\
\hline 1000 & 800 & 500 & 500 & 125 & 156 & 161 & 168 \\
\hline 1000 & 1000 & 500 & 500 & 130 & 163 & 171 & 180 \\
\hline 1000 & 800 & 600 & 400 & 125 & 156 & 161 & 168 \\
\hline 1000 & 600 & 400 & 400 & 92 & 124 & 126.5 & 144 \\
\hline
\end{tabular}




\section{CONCLUSION}

Two approaches, TCT-CC and TCT-GCC, are compared with a view to maximize the output power of the partially shaded PV array. The advantage with these approaches is that they operate only when partial shading occurs and remain inactive under uniform irradiance conditions, thereby avoiding the converter losses (except that occurring in the main DC-DC converter). Amongst the two approaches, it is observed that the TCT-GCC yields more power, about $2.9 \%$ to $4.5 \%$ than that of TCT-CC. The TCT-GCC is simple to design as is does not require isolated DC-DC converters. In addition, for TCT array configuration, it is more suitable than TCT-CC as there are practical constraints in the design of flyback converter with a rating exceeding $250 \mathrm{~W}$. Further, TCT-GCC has an upper hand in terms of reliability. In case if the switches of the multistage choppers fail to operate, the bypass diode connected across the switches serves the function of conventional bypass diodes connected across the PV modules, thereby preventing any damage to modules and simultaneously allowing the MPP tracker to extract higher power by operating near the GP. The highlight of the TCTGCC and the control scheme presented is the reduction in the number of converters and the sensors. The reduction in the number of converters is due to the TCT configuration adopted. The control scheme relies only on the voltage across the ties and the input current of the main boost converter. Thus, the TCT-GCC approach presented greatly reduces the cost, complexity and losses. Simulation results obtained in MATLAB/Simulink justifies the effectiveness of the TCTGCC approach in enhancing the power output of partially shaded array.

\section{REFERENCES}

[1] H. Patel and V. Agarwal, "MATLAB based modeling to study the effects of partial shading on PV array characteristics", IEEE Trans. Energy Conversion, vol. 23, no.1, pp. 302-310, March 2008.

[2] H.Patel and V. Agarwal, "Maximum power point tracking system forsystems operating under partially shaded condition", IEEE Trans. Ind. Electron., vol. 55, no.4, pp.1689-1698, April 2008.

[3] W.L. Chen and C.T. Tsai," Optimal balancing control for tracking theoretical global MPP of series PV modules subject to Partial Shading", IEEE Trans. Ind. Electron, vol. 62, no.8, pp.4837-4848, August 2015.

[4] L. Gao, R. A. Dougal, S. Liu, and A. P. Iotova, "Parallel-connected solarPV system to address partial and rapidly fluctuating shadow conditions,"IEEE Trans. Ind. Electron., vol. 56, no. 5, pp. 1548-1556, May 2009.

[5] F.Blaabjerg, R.Teodorescu, M.Liserre and A.V.Timbus, "Overview of control and grid synchronization for distributed power generationSystems", IEEE Trans. Ind. Electron., vol.53, no.5, pp. 13981409, October 2006.

[6] N.Femia, G. Lisi, G. Petrone, G. Spagnuolo, and M.Vitelli, "Distributedmaximum power point tracking of photovoltaic arrays : novel approachand system analysis", IEEE Trans. Ind. Electron., vol.55, no.7, pp. 2610-2621, July 2008.

[7] Z. Salam, M. Z. Ramli, "Distributed maximum power point tracker foradditional energy harvesting during partial shading of PV System", IEEE conf. on Smart Grid and Renewable Energy (SGRE), pp. 1-5, March 2015.

[8] G. AAdinolfi, G. Graditi, P. Siano, and A. Piccolo, "Multiobjectiveoptimal design of photovoltaic synchronous boost converters assessingefficiency, reliability and cost savings," IEEE Trans. Ind. Informat., vol. 11, no. 5, pp. 1038-1048, October 2015.
[9] Y. Nimni, D. Shmilovitz, "A retuned energy architecture for improvedphotovoltaic system efficiency", IEEE Int. Symp. Circuits and Systems, Paris, pp. 2191-2194, June 2011.

[10] Q. Zhang, X. Sun, Y. Zhong and M. Matsui "A novel topology for solving the partial shading problem in photovolatic power generation system," IEEE $6^{\text {th }}$ Int. Power Electron. Motion Control Conf. (IPEMC), Wuhan, pp. 2130-2135, May 2009.

[11] P. Sharma, P.K. Peter and V. Agarwal, "Exact maximum power point tracking of partially shaded PV strings based on current equalization concept", $38^{\text {th }}$ IEEE Photovoltaic Specialists Conf., Austin, USA, pp. 1411-1416, June 2012.

[12] P. Sharma and V. Agarwal, "Exact maximum power point tracking of grid-connected partially shaded PV source using current compensation concept," IEEE Trans. Power Electron., vol. 29, no. 3, pp. 4684-4692, September 2014.

[13] T. Shimizu, M. Hirakata, T. Kamezawa, and H. Watanabe, "Generation control circuit for photovoltaic modules," IEEE Trans. Power Electron, vol. 16, pp. 293-300, May 2001.

[14] T. Shimizu, O. Hashimoto, and G. Kimura, "A novel high-performance utility-interactive photovoltaic inverter system," IEEE Trans. Power Electro, vol. 18, pp. 704-711, March 2003.

[15] N. Shah and H. Patel, "Enhancing output power of PV array operating under non-uniform condition", $16^{\text {th }}$ IEEE Int. conf. on Environment and Electrical Engineering (EEEIC2016),Italy, pp. 1-6, June 2016.

[16] M. Jazayeri, S. Uysal, and K. Jazayeri, "A Comparative study on different photovoltaic array topologies under partial shading conditions", IEEE PES T\&D Conf. \& Exposition, pp. 1-5, USA, April 2014.

[17] B.J.G.Montano, D.J.F.Rombaoa, R.A.S.Peña and E.Q.B.Macabebe, "Effects of shading on current, voltage and power output of Total CrossTied photovoltaic array configuration", 10 region IEEE conf. TENCON, Macao, pp.1-5, November 2015.

[18] S. Vijayalakshmy, G.R. Bindu, S.R. Iyer, "Performance of partially shaded photovoltaic array configurations under shade dispersion", IEEE Int. Conf. Advances in Green Energy (ICAGE), Trivandrum, pp. 50-55, December 2014.

[19] B. I. Rani, G.S. Ilango and C. Nagamani,"Enhanced power generation from PV array under partial shading conditions by Shade dispersion using Su Do Ku configuration", IEEE Trans. on Sustainable Energy, vol.4, no.3, pp.594-601, April 2013.

[20] E.I. Batzelis, P.S. Georgilakis and S.A. Papathanassiou, "Energy models for photovoltaic systems under partialshading conditions: a comprehensive review", IET Renew. Power Generation, vol. 9, no.4, pp. 340-349, 2015.

[21] H. Sahu, S. Nayak, S. Mishra, "Maximizing the Power Generation of a Partially Shaded PV Array", IEEE J. Emerging Sel. Topics Power Electron, vol.4, no.2, pp.626-637.June 2016.

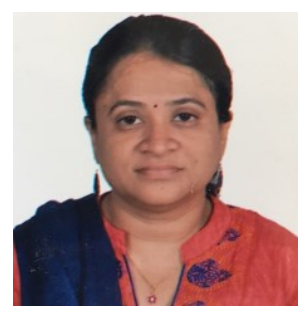

Neha Shah received the B.E. degree in electrical engineering from the S.V. Regional College of Engineering and Technology (now S.V. National Institute of Technology), South Gujarat University, Surat, India, in 2000, and the M.E. degree in Electrical engineering in 2003 from the M. S. University, Baroda,

\section{India.}

She is currently working as an Assistant Professor in Department of Electrical Engineering at Sardar Vallabhbhai Patel Institute of Technology, Vasad and pursuing the part time $\mathrm{Ph} . \mathrm{D}$. degree course in electrical engineering affiliated to Gujarat Technological University, Ahmedabad, Gujarat, India. Her current research interests include distributed generation, energy extraction from photovoltaic arrays, partial shading issues. She is a Life Member of the Indian Society for Technical Education and a member of IEEE. 


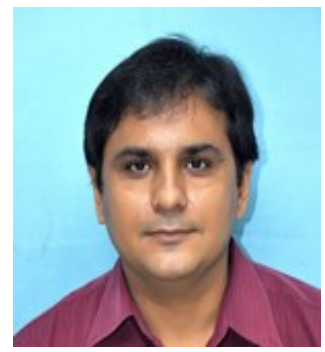

Hiren Patel received the B.E. degree in electrical engineering from the S.V. Regional College of Engineering and Technology (now S.V. National Institute of Technology), South Gujarat University, Surat, India, in 1996, and the M.Tech. degree in energy systems in 2003 from the Indian Institute of TechnologyBombay (IITB),Mumbai, India. He has received his Ph. D. degree from the Indian Institute of Technology in the year 2009. He is working as a Professor at Sarvajanik College of Engineering and Technology, Surat.

His current research interests include computer aided simulation techniques, distributed generation, and renewable energy, especially energy extraction from photovoltaic arrays. Mr. Patel is a Life Member of the Indian Society for Technical Education. 